\title{
Imported parasitic diseases in mainland China: current status and perspectives for better control and prevention
}

Lan-Gui Song ${ }^{1,2,3}$, Xing-Da Zeng ${ }^{1,2,3}$, Yan-Xia Li ${ }^{4}$, Bei-Bei Zhang ${ }^{1,2,3}$, Xiao-Ying Wu ${ }^{5}$, Dong-Juan Yuan ${ }^{1,2,3}$, $\mathrm{Ai} \mathrm{He} \mathrm{e}^{1,2,3^{*}}$ and Zhong-Dao $\mathrm{Wu}^{1,2,3^{*}}$

\begin{abstract}
Background: The high prevalence of parasitic diseases leads to millions of deaths and disabilities each year in developing countries. China has also been greatly affected by parasitic infections, including filariasis, leishmaniasis, malaria, schistosomiasis, and soil-transmitted nematodosis. However, the situation in China improved dramatically after comprehensive parasitic disease control efforts were strengthened, leading to the elimination of filariasis in 2006 and to significant control over other diseases. However, imported parasitic disease cases are inevitable, and such cases have increasingly been reported as a result of enhanced globalization and international or regional cooperation. These imported diseases represent a major obstacle to the elimination of several parasitoses, such as malaria.
\end{abstract}

Main text: This paper reviews imported cases of parasitic diseases in mainland China, particularly malaria and schistosomiasis, based on data reported separately by the Chinese annual reports and from other published papers. We summarize the new challenges that face parasitic disease control efforts in mainland China and perspectives regarding better control. We argue that both the provision of professional education and updated training for medical care personnel and the management and surveillance of people entering China are essential. We recommend that Chinese migrant workers should be considered a priority group for health education and that public awareness of imported diseases should be emphasized. Furthermore, we underscore the importance of investigating the distribution of introduced/potential vectors, parasite susceptibility, and improvements in diagnostic techniques and drug stocks.

Conclusions: Imported cases have become the main challenge to the elimination of several parasitoses, such as malaria and schistosomiasis, in mainland China. China should act to meet these challenges, which are closely associated with national biological safety.

Keywords: Parasitic diseases, Imported disease, China

\footnotetext{
*Correspondence: heai@mail.sysu.edu.cn; wuzhd@mail.sysu.edu.cn

'Department of Parasitology, Zhongshan School of Medicine, Sun Yat-sen

University, Guangzhou 510080, Guangdong, China

Full list of author information is available at the end of the article
}

(c) The Author(s). 2018 Open Access This article is distributed under the terms of the Creative Commons Attribution 4.0 International License (http://creativecommons.org/licenses/by/4.0/), which permits unrestricted use, distribution, and reproduction in any medium, provided you give appropriate credit to the original author(s) and the source, provide a link to the Creative Commons license, and indicate if changes were made. The Creative Commons Public Domain Dedication waiver (http://creativecommons.org/publicdomain/zero/1.0/) applies to the data made available in this article, unless otherwise stated. 


\section{Multilingual abstract}

Please see Additional file 1 for translations of the abstract into the five official working languages of the United Nations.

\section{Background}

Parasitic infections are considered diseases of poverty and are highly prevalent in developing countries, leading to millions of deaths and disabilities each year [1, 2]. Although humans in China previously suffered significantly from parasitic diseases [2], the rapid economic growth over the past six decades has led to the increased allocation of resources toward the control of parasitic diseases. Consequently, the status of parasitic diseases in China has improved considerably (Table 1) [3-9]. For instance, more than 30 million cases of lymphatic filariasis, a highly disfiguring infectious disease, were reported in 16 provinces/autonomous regions of mainland China during the $1950 \mathrm{~s}$. These cases included 5.4 million patients with severe disease who presented with signs such as elephantiasis, chyluria, hydroceles, and vaginal infection. After long-term efforts, China became the first developing country in the world to eliminate this parasitic disease in 2006 [3].

Leishmaniasis, or kala-azar disease, has been classified as one of the most neglected tropical diseases by the World Health Organization (WHO) and represents a serious global health burden [4]. Although China reported approximately 0.53 million patients with leishmaniasis in 16 provinces/autonomous regions during the early 1950s, this disease was nearly eliminated in 1958 by the large-scale treatment of infected dogs (reservoir hosts) and the use of antiparasitic drugs [4]. Approximately 400 new cases of this zoonotic parasite occur annually in China [5].

Malaria, which caused 445000 deaths in 2016, is the most devastating parasitic disease worldwide [10]. More than 24 million people in 24 provinces/autonomous regions of mainland China were estimated to suffer from malaria in the 1970s [11]. Following unrelenting efforts, a Chinese national malaria prevention and control program has progressed to the next stage, the Action Plan of China Malaria Elimination (2010-2020) [12]. Accordingly, malaria elimination has transformed from a concept to a fact, as demonstrated by the cases reported in mainland China during 2016: approximately $99.9 \%$ of the cases (3317 of 3321 ) were imported, whereas only $0.1 \%$ of the cases (3 of 3321) involved local infections in border regions such as Yunnan and Tibet [8].

Schistosomiasis is another debilitating parasitic disease with severe symptoms, such as hepatosplenomegaly, liver fibrosis, and upper gastrointestinal bleeding. In the 1950 s, schistosomiasis was estimated to affect 11.6 million people in mainland China, and the intermediate snail host, Oncomelania hupensis, is found in 14.3 billion square meters across 12 provinces/autonomous regions, leading to an infection risk for more than 100 million people who reside in these areas [7]. However, the number of schistosomiasis cases decreased to 54454 , and the schistosome infection rates of both humans and livestock decreased to less than 1\% throughout all 451 endemic counties in 2016 [13]. Accordingly, China is currently working toward the elimination of schistosomiasis and is expected to soon fulfill the goals outlined by the Healthy China 2030 Plan.

Echinococcosis, a natural-focal disease, is costly and complicated to treat because the treatment regimen generally involves extensive surgery followed by prolonged and intensive drug therapy. Estimates suggest that although 380000 persons acquired this infection in 2004 [14], the number of cases decreased to 40845 in 2015 following the implementation of the Action Plan for Echinococcosis Control (2010-2015) [9]. Nevertheless, echinococcosis remains challenging in China, and the control program should be continued and expanded.

Table 1 Previous and current status of the main parasitic diseases in mainland China

\begin{tabular}{|c|c|c|c|c|c|c|c|}
\hline \multirow[t]{2}{*}{ Parasitic diseases } & \multicolumn{2}{|c|}{ Estimated no. of patients } & \multicolumn{2}{|c|}{$\begin{array}{l}\text { Endemic provinces/ } \\
\text { autonomous regions }\end{array}$} & \multirow[t]{2}{*}{ Transmission vector } & \multirow[t]{2}{*}{ Transmission route } & \multirow[t]{2}{*}{$\begin{array}{l}\text { Elimination } \\
\text { program }\end{array}$} \\
\hline & Past (million) & Present & Past & Present $^{a}$ & & & \\
\hline Filariasis & 30 (1950s) & $0(2016)$ & 16 & 0 & Mosquito & Mosquito bites & Done \\
\hline Leishmaniosis & $0.53(1950 s)$ & $400 \pm$ annually $^{b}$ & 16 & $7^{c}$ & Sandfly & Sandfly bites & Almost done \\
\hline Malaria & 30 (1960s) & $3321(2016)$ & 24 & $2^{d}$ & Anopheline mosquito & Mosquito bites & Ongoing \\
\hline Schistosomiasis & 11.6 (1950s) & $54454(2016)$ & 12 & $7^{e}$ & Oncomelania hupensis & Infested water contact & Starting \\
\hline Echinococcosis & $0.38(2004)$ & $40845(2015)$ & 21 & $9^{f}$ & - & Fecal-oral route & - \\
\hline Soil-transmitted nematodosis & $536(1990)$ & $3.12 \%(2013)$ & 31 & $31^{\mathrm{g}}$ & - & Fecal-oral route/skin & - \\
\hline
\end{tabular}

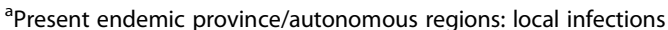

${ }^{\mathrm{b}}$ The prevalence of leishmaniosis in mainland China is not available; only annual new cases were found

'Seven provinces/autonomous regions: Xinjiang, Gansu, Sichuan, Shanxi, Shaanxi, Neimenggu, Henan

${ }^{\mathrm{d}}$ Three provinces/autonomous regions: Yunnan, Tibet

eSeven provinces/autonomous regions: Hunan, Jiangxi, Anhui, Hubei, Yunnan, Sichuan, Jiangsu

${ }^{f}$ Nine provinces/autonomous regions: Tibet, Qinghai, Neimenggu, Xinjiang, Shanxi, Gansu, Ningxia, Yunnan, Sichuan

${ }^{9}$ Data for Hong Kong, Macao and Taiwan Province were not available and are not included 
Soil-transmitted helminthiasis (i.e., infections with roundworms, pinworms, whipworms, and hookworms) is widely distributed throughout China. The prevalence of this condition has been extremely high, with positive rates of up to $53.67 \%$ (536 million infections) among individuals tested during the first national survey of human parasitic diseases in China conducted in 1990 [14]. A comprehensive surveillance system and integrated control campaign launched in 2006 have led to a steady and apparent decline in nematodiasis, with average infection rates of $20.88,18.93,16.59,13.30,11.25$, $9.67,6.90$, and $3.12 \%$ in 2006, 2007, 2008, 2009, 2010, 2011, 2012, and 2013, respectively [6]. These data demonstrate the remarkable achievements in local parasitic diseases control throughout China and indicate that these efforts toward the prevention and control of parasitic diseases should be continued.

However, new imported cases of parasitic diseases are inevitable and will likely become increasingly common due to enhanced globalization as well as international and regional communication and cooperation. Estimates suggest that as many as 244 million people worldwide were living outside their countries of birth in 2015 [15]. Travel exchanges between different environments play a crucial role in the successful management of parasitic diseases in migrant receiving countries, particularly in cases in which vectors (e.g., snails, mosquitoes) are also present in China and may thus induce local infections.

\section{Main text}

Review of imported parasitic diseases in mainland China Figure 1 presents the entire literature review process. First, annual reports from the Chinese Center for Disease Control and Prevention (published in Malaria Situation in the People's Republic of China and Endemic status of schistosomiasis in People's Republic of China) were examined. Relevant data (reported province/autonomous regions, source country/province, parasite species) were extracted, processed, and analysed using Excel 2013 (Microsoft Corp., Redmond, WA, USA). Then, a systematic literature search was conducted in CNKI (http://cnki. net/), Wanfang (http://new.wanfangdata.com.cn/) and PubMed (https://www.ncbi.nlm.nih.gov/pubmed) about the imported parasitic diseases in mainland China. The retrieval time: From Jan 1980 to Jan 2018. The keywords "imported and (Malaria or Schistosomiasis or Trypanosomiasis or Loaiasis or Echinococcosis or Soil-transmitted helminthiasis or Filariasis or Leishmaniosis) and China". All identified papers were screened. Inclusive criteria: (1) Studies that were published from Jan 1980 to Jan 2018; (2) Studies that were published in Chinese or English; (3) Studies that focused on imported parasitic diseases in mainland China. Exclusion criteria: (1) Cases containing overlapping data; (2) Cases without details (age, sex, occupation, travel history, diagnostic process, reported province/autonomous regions, source country/province, parasite species). Relevant data were extracted, processed, and analysed using Excel 2013.

\section{Current status of imported parasitic diseases Imported malaria}

Although malaria was once highly prevalent in 24 provinces/autonomous regions of China, local infections were reported in only Yunnan and Tibet in 2016 [8, 12]. However, except for Tibet, the remaining 30 provinces/autonomous regions in mainland China reported imported cases in the latest Chinese annual report (2016) [8]. The top five provinces/autonomous regions in terms of reported cases imported from abroad (i.e., Chinese residents who acquire an infection abroad and return to China or

\begin{tabular}{|c|c|c|c|c|}
\hline \multicolumn{5}{|c|}{ Literature searching } \\
\hline & & & $\downarrow$ & \\
\hline \multicolumn{2}{|c|}{ Chinese annual reports ${ }^{a}$} & \multicolumn{3}{|c|}{$\begin{array}{l}\text { Two Chinese databases } \\
\text { AND Pubmed }{ }^{b}\end{array}$} \\
\hline & & & & \\
\hline malaria & schistosomiasis & malaria & schistosomiasis & others \\
\hline 28 reports & 18 reports & $247+17$ reports & $67+2$ reports & $36+2$ reports \\
\hline \multicolumn{2}{|c|}{$\begin{array}{l}\text { Reports without details or } \\
\text { imported cases removed }\end{array}$} & \multicolumn{3}{|c|}{$\begin{array}{c}\text { Irrelevant, duplicate or incomplete } \\
\text { cases removed }\end{array}$} \\
\hline 14 reports & 15 reports & 113 papers & 16 papers & 6 papers \\
\hline $2002-2016$ & $2001-2016$ & 225 cases & 29 cases & 10 cases \\
\hline
\end{tabular}

Fig. 1 Overall process of reviewing Chinese annual reports and other literature. ${ }^{a}$ Chinese annual reports: annual Malaria Situation in the People's Republic of China collected for Chin J Parasitol Parasit Dis (1988-2016; 2001 was not available) and annual Endemic status of schistosomiasis in People's Republic of China collected from Chin J Schisto Control (1999-2016). ' ${ }^{\text {T }}$ wo (largest) Chinese databases: CNKI and Wanfang; one English database search engine: PubMed 
foreign travellers who acquire an infection in their own country before traveling to China) were Yunnan, Guangxi, Jiangsu, Sichuan, and Henan during 2011 and 2016. The five main source countries of these malarial infections were Myanmar, Ghana, Angola, Equatorial Guinea, and Nigeria during 2011 and 2014 (Table 2) [8, 16-20]. During 2011 and 2016, Plasmodium falciparum malaria was most common, causing $61.5 \%$ of cases, followed by $P$. vivax malaria $(27.8 \%), P$. ovale malaria (5.1\%) and P. malariae malaria (1.4\%) (Table 3) [8, 1620]. One case of $P$. knowlesi malaria was reported in 2014 [19]. Countries that share borders with China, such as Myanmar, continue to suffer intensely from malaria, and this fact presents an obstacle to the elimination of local infections in Chinese border regions [8]. Accordingly, a few cases of domestically mobile (i.e., imported inter- and intra-provincially) infection have been reported annually over the past five years $[8,16-20]$.

The literature reports of imported malaria cases are not fully consistent with those reported by the Chinese annual report [21-111]. For instance, Yunnan Province reported most of the imported cases in the past consecutive three annual reports (2014-2016), but Hubei Province reported most of the imported cases in the other literature reports from 1986 to 2017, and the proportion of $P$. falciparum malaria was higher in literature reports $(75 \%)$ than in the Chinese annual report (65\% in 2016). Both the literature and Chinese annual reports described similar source countries, and both ranked Myanmar first. Among the 113 imported malaria cases from literature from 1986 to 2017, 108 (95.6\%) were identified in men; this was likely because 73 of the cases $(64.6 \%)$ involved migrant workers from Africa or Southeast Asia from 2000 to 2017. Twelve deaths $(10.6 \%)$ were reported and attributed to misdiagnosis or delayed treatment from 1989 to 2013. Only a few domestically mobile cases were reported, and all occurred at least ten years ago [112-124].

\section{Imported schistosomiasis}

Of the five main types of schistosomiasis, only schistosomiasis japonica is prevalent in China [7]. Transmission of this disease has already ceased in six (Sichuan, Zhejiang, Shanghai, Fujian, Guangdong, and Guangxi) of the original 12 endemic provinces/autonomous regions, but cases continue to occur in Yunnan, Jiangsu, Hubei, Anhui, Hunan, and Jiangxi [7, 125]. Therefore, schistosomiasis japonica remains domestically mobile in China. A summary of imported cases of schistosomiasis (Chinese annual reports) in mainland China from 2001 to 2016 is provided in Additional file 2 [13, 126-140]. Only four cases of schistosomiasis mansoni imported from abroad were reported in Beijing $(2008,2010)$ and Zhejiang (2013, 2015), and two cases of schistosomiasis haematobia were reported in Zhejiang in 2016. Overall, 123 chronic and 65 acute imported cases of schistosomiasis japonica were reported during 2011 and 2016 and were mainly distributed in Zhejiang and Shanghai.

The relevant literature from 1999 to 2016 is displayed in Table 4. Nine schistosomiasis cases imported from abroad have been reported, of which eight involved Chinese migrant workers returning from Africa (Angola, Nigeria and Tanzania) and the ninth involved a businessman returning from Ghana [141-148]. Twenty domestically mobile cases were reported in mainland China [149-155], fifteen of which involved transmission from non-endemic or transmission-disrupted areas to endemic areas wherein patients were infected upon returning to their hometowns. The remaining five patients were migrant workers from endemic areas in Zhejiang (a transmission-disrupted province).

Table 2 Five main reported provinces/autonomous regions in mainland China and source countries associated with cases of malaria imported from abroad (Chinese annual report) from 2011 to 2016

\begin{tabular}{|c|c|c|c|c|c|c|c|c|c|c|c|}
\hline \multirow[t]{2}{*}{ Year } & \multirow{2}{*}{$\begin{array}{l}\text { No. of reported } \\
\text { provinces/ } \\
\text { autonomous } \\
\text { regions }\end{array}$} & \multicolumn{5}{|c|}{ No. of cases from five main reported provinces/autonomous regions } & \multicolumn{5}{|c|}{ No. of cases from five main source countries } \\
\hline & & YN & GX & JS & SC & $\mathrm{HN}$ & Myanmar & Ghana & Angola & Equatorial Guinea & Nigeria \\
\hline 2016 & 30 & 410 & 305 & 307 & 327 & 198 & - & - & - & - & - \\
\hline 2015 & 31 & 585 & 236 & 405 & 290 & 184 & - & - & - & - & - \\
\hline 2014 & $30^{a}$ & 486 & 184 & 355 & 264 & 216 & 488 & 188 & 278 & 289 & 330 \\
\hline 2013 & $30^{b}$ & 513 & 1251 & 341 & 234 & 194 & 608 & 1345 & 442 & 296 & 217 \\
\hline 2012 & $29^{c}$ & 679 & 219 & 198 & 148 & 150 & 764 & 241 & 151 & 233 & 197 \\
\hline 2011 & 25 & 1086 & 111 & 357 & 172 & 184 & 1148 & 88 & 277 & 199 & 243 \\
\hline Total & - & 3759 & 2306 & 1963 & 1435 & 1126 & 3008 & 1862 & 1148 & 1017 & 987 \\
\hline
\end{tabular}

YN: Yunan; GX: Guangxi; JS: Jiangsu; SC: Sichuan; HN: Henan

Mainland China has 31 provinces (Hong Kong, Macao, and Taiwan Province not included)

${ }^{\mathrm{a}}$ Except for Neimenggu; ${ }^{\mathrm{b}}$ except for Tibet; ${ }^{\mathrm{c}}$ except for Tibet and Qinghai 
Table 3 Numbers of cases (Chinese annual report) of each type of malaria imported from abroad in mainland China from 2011 to 2015

\begin{tabular}{|c|c|c|c|c|c|c|c|c|c|c|c|c|c|c|c|}
\hline \multirow[t]{2}{*}{$\begin{array}{l}\text { Diagnosis } \\
\text { year }\end{array}$} & \multirow[t]{2}{*}{$\begin{array}{l}\text { No. of } \\
\text { cases }\end{array}$} & \multicolumn{2}{|c|}{$\begin{array}{l}\text { P. falciparum } \\
\text { malaria }\end{array}$} & \multicolumn{2}{|c|}{$\begin{array}{l}\text { P. vivax } \\
\text { malaria }\end{array}$} & \multicolumn{2}{|c|}{$\begin{array}{l}\text { P. ovale } \\
\text { malaria }\end{array}$} & \multicolumn{2}{|c|}{$\begin{array}{l}\text { P. malariae } \\
\text { malaria }\end{array}$} & \multicolumn{2}{|c|}{$\begin{array}{l}\text { Mixed } \\
\text { infection }\end{array}$} & \multicolumn{2}{|c|}{$\begin{array}{l}\text { Unidentified } \\
\text { type }\end{array}$} & \multicolumn{2}{|c|}{$\begin{array}{l}\text { P. knowlesi } \\
\text { malaria }\end{array}$} \\
\hline & & No. & $\%$ & No. & $\%$ & No. & $\%$ & No. & $\%$ & No. & $\%$ & No. & $\%$ & No. & $\%$ \\
\hline 2016 & 3317 & 2158 & 65.1 & 709 & 21.4 & 311 & 9.4 & 64 & 1.9 & 61 & 1.8 & 14 & 0.4 & 0 & 0.0 \\
\hline 2015 & 3248 & 1991 & 61.3 & 851 & 26.2 & 272 & 8.4 & 70 & 2.2 & 47 & 1.5 & 17 & 0.5 & 0 & 0.0 \\
\hline 2014 & 3021 & 1876 & 62.1 & 798 & 26.4 & 231 & 7.7 & 52 & 1.7 & 44 & 1.5 & 19 & 0.6 & 1 & 0.0 \\
\hline 2013 & 4042 & 2899 & 71.7 & 859 & 21.2 & 133 & 3.3 & 51 & 1.3 & 65 & 1.6 & 35 & 0.9 & 0 & 0.0 \\
\hline 2012 & 2474 & 1403 & 56.7 & 901 & 36.4 & 28 & 1.1 & 28 & 1.1 & 39 & 1.6 & 75 & 3.0 & 0 & 0.0 \\
\hline 2011 & 2974 & 1414 & 47.6 & 1183 & 39.8 & 0 & 0.0 & 0 & 0.0 & 99 & 3.3 & 278 & 9.4 & 0 & 0.0 \\
\hline Total & 19076 & 11741 & 61.5 & 5301 & 27.8 & 975 & 5.1 & 265 & 1.4 & 355 & 1.9 & 438 & 2.3 & 1 & 0.0 \\
\hline
\end{tabular}

\section{Other imported parasitic diseases}

A literature-based list of imported parasitic diseases other than malaria and schistosomiasis in mainland China is presented in Table 5 [156-161].

\section{Perspectives for better control and prevention}

Estimates suggest that as many as 244 million people worldwide are living outside their country of birth [15], and travel between different environments plays a crucial role in the management of parasitic diseases in countries that receive migrants. In other words, imported parasitic diseases are unavoidable. The China Africa Project, which aimed to assist with infrastructure construction, has led to a dramatic increase in the number of migrant workers who have moved to Africa since the 1970s [7]. In addition, increasing numbers of Chinese companies, particularly the communications industries, have established overseas subsidiaries over the past decade to capitalize on the African market. Current estimates indicate that more than 1 million Chinese live in Africa [7]. These individuals lack knowledge about self-protection and are at risk of acquiring schistosomiasis while swimming in unclean water, developing malaria after failing to protect against mosquito bites, or contracting other parasitic infections by eating infected food. This situation is exacerbated by a failure to report their travel history to a physician. Because

Table 4 Domestically mobile cases of schistosomiasis and those imported from abroad in mainland China from 1999 to 2016 (literature-based)

\begin{tabular}{|c|c|c|c|c|c|c|c|}
\hline Diagnosis year & Reported province & Sex & Age & Source country/province & Activity/occupation & Diseases $^{c}$ & Ref \\
\hline 2016 & Fujian & $1 \mathrm{M}$ & 30 & Angola & Migrant worker ${ }^{a}$ & Sh & 141 \\
\hline 2015 & Shandong & $1 \mathrm{M}$ & 38 & Angola & Migrant worker ${ }^{a}$ & Sh & 142 \\
\hline 2015 & Zhejiang & $1 \mathrm{M}$ & 52 & Nigeria & Migrant worker ${ }^{a}$ & Sh & 143 \\
\hline 2015 & Zhejiang & $1 \mathrm{M}$ & 53 & Nigeria & Migrant worker ${ }^{a}$ & Sh & 144 \\
\hline 2013 & Zhejiang & $1 \mathrm{M}$ & 46 & Nigeria & Migrant worker ${ }^{a}$ & Sm & 145 \\
\hline 2012 & Shanxi & $1 \mathrm{M}$ & 36 & Angola & Migrant worker ${ }^{a}$ & Sh & 146 \\
\hline 2012 & Fujian & $1 \mathrm{M}$ & 25 & Ghana & businessman & Sh & 147 \\
\hline 2011 & Henan & $1 \mathrm{M}$ & 40 & Angola & Migrant worker ${ }^{a}$ & Sh & 148 \\
\hline 2011 & Henan & $1 \mathrm{M}$ & 33 & Tanzania & Migrant worker ${ }^{a}$ & Sh & 148 \\
\hline 2009 & Jiangsu & $1 \mathrm{M} 1 \mathrm{~F}$ & 9 & Jiangxi & Student & Sj & 149 \\
\hline 2005 & Guizhou & $8 M$ & $30-54$ & Hubei/Hunan & Catch birds & Sj & 150 \\
\hline 2005 & Zhejiang & $1 \mathrm{M}$ & 18 & Anhui & Migrant worker ${ }^{b}$ & Sj & 151 \\
\hline 2004 & Zhejiang & $1 \mathrm{M}$ & 49 & Hubei & Migrant worker ${ }^{b}$ & Sj & 151 \\
\hline 2004 & Zhejiang & $1 \mathrm{~F}$ & 41 & Sichuan & Migrant worker ${ }^{b}$ & Sj & 152 \\
\hline 2003 & Zhejiang & $1 \mathrm{M}$ & 36 & Anhui & Migrant worker ${ }^{b}$ & Sj & 153 \\
\hline 2003 & Zhejiang & $1 M$ & 24 & Hubei & Migrant worker ${ }^{b}$ & Sj & 153 \\
\hline 2000 & Guangdong & $1 \mathrm{M}$ & 19 & Hunan & Shipbuilder & Sj & 154 \\
\hline 1999 & Zhejiang & $1 \mathrm{M}$ & 39 & Anhui & Fish farming & Sj & 155 \\
\hline
\end{tabular}

$M$ Male, $F$ Female

${ }^{a}$ Migrant worker to Africa; ${ }^{b}$ Migrant worker to another province/autonomous regions in mainland China

'Sh: Schistosomiasis haematobia; Sm: Schistosomiasis mansoni; Sj: Schistosomiasis japonica 
Table 5 Abroad-imported cases of other parasitic diseases in mainland China (literature-based)

\begin{tabular}{llllllll}
\hline Diagnosis year & Reported province/autonomous regions & Sex & Age & Source country & Activity/occupation & Diseases & Ref \\
\hline 2017 & Fujian & F & 41 & Kenya/Tanzania & Travel & Trypanosomiasis & 156 \\
2015 & Beijing & M & 49 & Congo & Migrant worker & Loaiasis & 157 \\
2015 & Beijing & M & 28 & Nigeria & Cartwright & Loaiasis & 158 \\
2015 & Beijing & M & 49 & Congo & Migrant worker & Loaiasis & 158 \\
2014 & Jiangsu & M & 45 & Gabon & Migrant worker & Trypanosomiasis & 159 \\
2013 & Beijing & M & 33 & Gabon/Cameroun & Migrant worker & Loaiasis & 158 \\
2012 & Beijing & M & 25 & Gabon & Engineer & Loaiasis & 158 \\
2012 & Beijing & M & 23 & Cameroun & Translator & Loaiasis & 158 \\
2008 & Zhejiang & M & 45 & Gabon & Farming & Loaiasis & 160 \\
2008 & Zhejiang & M & 45 & Gabon & Migrant worker & Loaiasis & 161
\end{tabular}

$M$ Male, $F$ Female

many physicians in China are somewhat unfamiliar with parasitology, this omission presents an obstacle to a correct diagnosis [162]. The Belt and Road Initiative, proposed in 2013 by Chinese president Xi Jinping, aimed to build a trade and infrastructure network that would connect Asia with Europe and Africa along the land-based Silk Road Economic Belt and the ocean-based Maritime Silk Road. More than 100 countries and international organizations are or will be involved in this program, which will affect nearly two-thirds of the global population and approximately a quarter of all goods and services needed for global functioning [163]. Undoubtedly, however, this program will present new challenges to Chinese parasitic disease control programs. The detection of imported cases and the provision of prompt treatment will be essential to reducing the risk of an outbreak of parasitic disease, particularly of nonindigenous parasites, as the establishment of a new parasite may lead to catastrophic consequences. Therefore, universal participation in the campaign against imported parasitic diseases in mainland China is required and includes the transmission of information regarding health care organizations (clinics and hospitals), disease control and prevention centers (CDC), governmental public health departments, entry and exit administrations, labour service companies, transnational corporations, and tourist administrations.

\section{Strengthening the essentiality of professional education and updated training for medical care personnel}

The parasitic disease control program in China has made impressive progress, and its status is particularly important, particularly with regard to the rapidly developing economy in mainland China. This program is especially essential to highly developed areas such as Guangdong, Shanghai, and Beijing, where fewer resources are available to communicate knowledge about parasitic diseases [162]. In the absence of sufficient financial resources, general practitioners and specialists might no longer be equipped with sufficient parasitological knowledge. Accordingly, primary health care providers might misdiagnose many cases of malaria as a cold or flu, leading to delayed treatment $[26,45,64,70,79,81]$. As a result, some patients might not receive an accurate diagnosis even after referral to a specialist $[57,63,68,71]$, and the resulting treatment delay may be lethal for patients infected with $P$. falciparum.

Furthermore, technicians may not be able to differentiate Plasmodium species in blood smears [26, 34, $42,94,105]$, especially in small hospitals without DNA detection-related equipment, and patients with $P$. falciparum co-infection have died after receiving a diagnosis of the less-serious $P$. vivax malaria $[20,105]$. A recent report describes the case of a 36-year-old male migrant worker who was misdiagnosed with a ureteral calculus, invasive urothelial carcinoma, and eosinophilic cystitis at several hospitals after returning from Angola. The patient underwent several treatments, including transurethral bladder tumor resection, before finally receiving a definite diagnosis of schistosomiasis haematobia after a pathology examination revealed eggs in the bladder tissue [146]. The eventual diagnosis occurred one year after his first visit to the clinic, and his subsequent experience had both physical and mental effects. Similarly, more than two months were required to receive a final diagnosis in the first case of human African trypanosomiasis in China. During this delay, the trypanosome parasites were able to cross the blood-brain barrier and enter the spinal fluid to infect the central nervous system, leading to irreversible damage [159]. Although imported cases are difficult to diagnose, much can be done to avoid future tragedies. Among medical care personnel, the awareness of parasitic diseases and parasitological knowledge must be improved. Professional parasitological education should 
be strengthened, rather than neglected, in medical schools. Furthermore, regular training courses are needed to ensure that relevant medical personnel receive updated knowledge and improve their expertise.

\section{Putting Chinese migrant workers as a priority group for health education and public awareness of imported diseases}

As mentioned above, the number of Chinese migrant workers is expected to increase rapidly to meet the goals of large Chinese governmental programs such as "Aid to Africa" and the Belt and Road Initiative. Most migrant workers will participate in outdoor work projects, including the construction of water reservoirs, electric power stations, and roads and in mining and oil exploitation. These workers tend to have a lower socioeconomic status and education level and are thus less likely to possess adequate health knowledge. Accordingly, they are vulnerable to environmental risk factors such as contact with unsafe water and insect bites and are therefore very susceptible to parasitic infection. Therefore, labour service companies must conduct health education activities, distribute medicine, and provide necessary personal protective equipment to the migrant workers before they leave China. Governmental health departments should also provide guidance and supervision during this process. In practice, however, these procedures fall short of the targets. Some returnees understand that they might have developed malaria if they have a fever, and this knowledge can help the physician make a timely diagnosis [81]. More commonly, however, the returnee does not know what type of disease he or she might have acquired, and the connection between the disease and health risk behaviour remains hidden. Furthermore, some returnees do not report their travel history to the physician, which contributes significantly to misdiagnosis $[75,101]$. Accordingly, more resources should be allocated to the health education of prospective migrant workers. For example, CDCs could assign professionals to deliver informative lectures to those workers. Other people, such as businessmen, students, technicians, and travelers, are also susceptible to parasitic infection. Therefore, information departments and tourist administrations should also raise awareness of the potential dangers by distributing brochures, displaying posters, and playing promotional videos.

\section{Intensifying the management and surveillance of people entering China (international and domestic passengers)}

Imported parasitic diseases are an inevitable and increasingly common consequence of globalization, as well as international and regional communications and cooperation. Issues related to the management and surveillance of people entering China are broad, high-level, and cross-cutting. Travel between different environments will inevitably result in the importation of parasitic disease agents and the introduction of new parasites to China. In the absence of a sound management and surveillance system, such travel might lead to the formation of an endemic focus, especially if the parasite vector (snail, mosquito) is present in China.

The number of domestic travellers continues to grow steadily, as demonstrated by the increasing number of Chinese travellers to other countries $(101,117$, and 122 million person-times in 2014, 2015, and 2016, respectively) [164-166]. The number of international visitors (and compatriots from Hong Kong, Macao, and Taiwan Province) has also increased (128, 134, and 138 million persons in 2014, 2015, and 2016, respectively) [164-166]. While traveling, domestic passengers might acquire certain infections because of a lack of knowledge about transmission and a lack of specific antibodies. These factors are especially important for travelers who visit Africa and Southeast Asia and for international visitors from endemic areas who may have already developed or will develop the disease. Thus, entry inspection plays a vital role in the management of such potential infection sources. The CDC staff should monitor the health service usage and health outcomes of suspected or confirmed cases of a certain parasitic diseases. For example, the condition of a 43-year-old migrant worker with falciparum malaria worsened after a failure to comply with medical instructions provided by the CDC staff [44]. The development of management and surveillance guidelines, particularly for non-endemic parasitic diseases, is increasing in importance.

\section{Increasing investigation of the distribution of introduced/ potential vectors and susceptibility to parasites}

The Chinese population is increasingly at risk of contracting parasitic diseases that are not indigenous to China as a result of the return of infected travelers or the arrival of infected foreigners $[167,168]$. The risk of transmission of such diseases increases when the parasite vectors are present in or have been introduced to China. The natural S. mansoni vector, Biomphalaria straminea, was found in Hong Kong in 1974. In 2013, its distribution was found to have expanded to nearby cities such as Shenzhen, Dongguan, and Huizhou, Guangdong, and it might since have spread via waterways in Guangdong [7]. Because the Guangdong region is characterized by many rivers and frequent international communications, the parasite's life cycle may be established by the introduction of patient fecal matter into water containing Biomphalaria snails. This would be a matter of great public concern. For other nonindigenous parasitic diseases such as Chagas disease (Trypanosoma cruzi), the vector (triatomine insects) 
was found to be distributed throughout China [169], although the susceptibility of the vector to T. cruzi remains unclear. Therefore, it is important to understand both the distribution of the vectors and their susceptibilities to parasites. The CDC staff and scientific researchers should collaborate to conduct relevant field investigations and laboratory research.

\section{Improving diagnostic techniques and drug stocks}

Many parasitic diseases are clinically curable if treatment is initiated at an early stage. Therefore, universal access to rapid diagnosis and care is essential. However, the diagnosis of an imported parasitic disease is complex and requires specialized staff, because many diagnostic techniques are far from satisfactory. For example, the current rapid diagnostic tests for malaria are somewhat unreliable, and repeated false-negative cases $[46,61,86]$ have led to multiple missed diagnoses at ports of entry and community health care centres. Although the microscopic examination of a peripheral blood smear is currently the gold standard for malaria diagnosis, this technique is limited by a high false-negative rate [41, 84], especially in cases with low degrees of parasitemia. Furthermore, it is difficult to differentiate among Plasmodium species, and coinfections are often missed [27]. Although DNA detection techniques have been developed to overcome these limitations [21], these methods are much more expensive, and each small clinic cannot realistically be supplied with an expensive PCR amplifier and skilled technicians. Accordingly, early, rapid, economically feasible, and accurate diagnostic methods are in desperate demand. Foundations should support studies in this field and encourage researchers to conduct related studies. In addition, because the rapid diagnosis of an imported parasitic disease is meaningless without prompt treatment, access to therapeutic interventions for rare parasitic diseases is also a significant factor. The CDC should establish a secure drug supply system to guarantee that patients with rare infections can obtain timely therapeutic interventions.

\section{Conclusions}

In the context of globalization, which is underscored by large Chinese governmental programs such as "Aid to Africa" and the "Belt and Road Initiative", the Chinese parasitic disease control program will face new challenges. For example, imported cases of disease represent a major obstacle to the elimination of several parasitoses such as malaria and schistosomiasis, and some nonindigenous pathogens (and their vectors) have emerged in mainland China. Therefore, China should act to meet these challenges, which are closely associated with national biological safety.

\section{Additional files}

Additional file 1: Multilingual abstracts in the five official working languages of the United Nations. (PDF $349 \mathrm{~kb}$ )

Additional file 2: Chinese annual report-based details of imported cases of schistosomiasis in mainland China from 2001 to 2016. (PDF 99 kb)

Abbreviations

CDC: Centers for Disease Control and Prevention

\section{Acknowledgements}

We thank Professor Heinz Mehlhorn (Heinrich Heine University, Germany) and Professor Moussa Sacko (Ministry of Health, Mali) for providing helpful comments and suggestions.

\section{Funding}

This work was supported by grants from the National Key R\&D Program of China (No. 2016YFC1200500), the National Natural Science Foundation of China (No. 81601781) and the China Postdoctoral Science Foundation (No. KLF201012).

\section{Availability of data and materials}

The datasets used and/or analysed during the current study are available from the corresponding author upon reasonable request.

\section{Authors' contributions}

ZD-W directed and coordinated the study. LG-S and XD-Z were responsible for the literature review. LG-S analysed the data, drew the images and wrote the first draft. XD-Z, YX-L, BB-Z, XY-W, DJ-Y and ZD-Wu revised the manuscript. All authors read and approved the final manuscript.

Ethics approval and consent to participate

Not applicable.

\section{Consent for publication}

Not applicable.

\section{Competing interests}

The authors declare that they have no competing interests.

\section{Author details}

${ }^{1}$ Department of Parasitology, Zhongshan School of Medicine, Sun Yat-sen University, Guangzhou 510080, Guangdong, China. ${ }^{2}$ Key Laboratory of Tropical Diseases Control (SYSU), Ministry of Education, Guangzhou 510080, Guangdong, China. ${ }^{3}$ Provincial Engineering Technology Research Center for Biological Vector Control, Guangzhou 510080, Guangdong, China. ${ }^{4}$ Jiangxi Provincial Testing Center of Medical Apparatus and Instruments, Nanchang 330029, Jiangxi, China. ${ }^{5}$ School of Public Health, Fudan University, Shanghai 200433, China.

Received: 12 February 2018 Accepted: 19 June 2018 Published online: 03 August 2018

\section{References}

1. Zhou XN. Prioritizing research for "one health-one world". Infect Dis Poverty. 2012;1(1):1.

2. Wang JL, Li TT, Huang SY, Cong W, Zhu XQ. Major parasitic diseases of poverty in mainland China: perspectives for better control. Infect Dis Poverty. 2016:5:67.

3. Sun DJ, Deng XL, Duan JH. The history of the elimination of lymphatic filariasis in China. Infect Dis Poverty. 2013;2:30.

4. Lun ZR, Wu MS, Chen YF, Wang JY, Zhou XN, Liao LF, et al. Visceral Leishmaniasis in China: an endemic disease under control. Clin Microbiol Rev. 2015:28(4):987-1004.

5. Li YF, Zhong WX, Zhao GH, Wang HF. Prevalence and control of kala-azar in China. J Pathogen Bio. 2011;6(8):629-31. (in Chinese)

6. Chen YD, Jian W. Current situation of soil-transmitted nematodiasis monitoring in China and working keys in future. Chin J Schisto Control. 2015;27(2):111-4. (in Chinese) 
7. Song LG, Wu XY, Sacko M, Wu ZD. History of schistosomiasis epidemiology, current status, and challenges in China: on the road to schistosomiasis elimination. Parasitol Res. 2016;115(11):4071-81.

8. Zhang L, Feng J, Zhang SS, Jiang S, Xia ZG, Zhou SM. Malaria situation in the People's Republic of China in 2016. Chin J Parasitol Parasit Dis. 2017; 35(6):515-9. (in Chinese)

9. Wang LY. Prev Control of Hydatid disease: evaluation on "12th Five-year Plan" and perspectives for "13th Five-Year Plan". Chin Animal Health. 2017; 19(7):13-17. (in Chinese).

10. World Health Organization. World Malaria Report 2017. 2017. http://www. who.int/malaria/publications/world-malaria-report-2017/en/. Accessed 29 November 2017

11. Tao ZY, Fang Q, Liu XL, Culleton R, Tao L, Xia H, et al. Congenital Malaria in China. PLoS Negl Trop Dis. 2014;8(3):e2622.

12. Lu G, Zhou S, Horstick O, Wang X, Liu Y, Müller O. Malaria outbreaks in China (1990-2013): a systematic review. Malar J. 2014;13:269.

13. Zhang LJ, Xu ZM, Qian YJ, Dang H, Lv S, Xu J, et al. Endemic status of schistosomiasis in People's Republic of China in 2016. Chin J Schisto Control. 2017;29(6):669-77. (in Chinese)

14. Xu LQ, Chen YD, Sun FH, Cai L, Fang RY, Wang LP, et al. National investigation of China on human parasitic diseases situation. Chin J Parasitol Parasit Dis. 2005;23(5):332-40. (in Chinese)

15. United Nations. International migration report 2015. 2016. http://www.un. org/en/development/desa/population/migration/publications/ migrationreport/docs/MigrationReport2015.pdf. Accessed Sept 2016.

16. Xia ZG, Yang MN, Zhou SS. Malaria situation in the People's Republic of China in 2011. Chin J Parasitol Parasit Dis. 2012;30(6):419-21. (in Chinese)

17. Xia ZG, Feng J, Zhou SS. Malaria situation in the People's Republic of China in 2012. Chin J Parasitol Parasit Dis. 2013;31(6):413-6. (in Chinese)

18. Zhang L, Feng J, Xia ZG. Malaria situation in the People's Republic of China in 2013. Chin J Parasitol Parasit Dis. 2014;32(6):407-9. (in Chinese)

19. Zhang L, Zhou SS, Feng J, Fang W, Xia ZG. Malaria situation in the People's Republic of China in 2014. Chin J Parasitol Parasit Dis. 2015;33(5):319-24. (in Chinese)

20. Zhang L, Fen J, Zhang SX, Xia ZG, Zhou SS. Malaria situation in the People's Republic of China in 2015. Chin J Parasitol Parasit Dis. 2016;34(6):477-81. (in Chinese)

21. Zhu XC, Wang Y. Investigation and analysis of a cases of imported malaria: mixed infection of Plasmodium falciparum and Plasmodium vivax. Chin J Vector Bio \& Control. 2008;19(1):16. (in Chinese)

22. Zhang P, Li CL, Zhang M, Chen HF, Yang ZP. Epidemiological investigation on one death case of imported Plasmodium falciparum. Modern Preventive Med. 2014;41(16):2884-5. (in Chinese)

23. Wang XG, Lei $Y L$, Lan JQ, Mei JH, Li ZH. Laboratory testing for a case of imported Plasmodium ovale infection in Zhejiang Province. Chin J Parasito Parasit Dis. 2013;31(1):78-9. (in Chinese)

24. Liu Q, Liu H, Pan AG, Xia JX, Tang X. Epidemiological investigation on imported Plasmodium falciparum case of mount E'mei city of Sichuan Province in 2014. Parasitoses Infect Dis. 2016;14(2):112-4. (in Chinese)

25. Liu Y, Zhang P, Liu F. Case report: three case of imported Plasmodium falciparum in Yongqiao district of Shuzhou city in 2015. J Trop Dis Parasitol. 2016;14(2):100-1. (in Chinese)

26. Yan T, Li ZF, Ling H, Zhou Y, Xu JR. Laboratory diagnosis on three cases of imported Plasmodium ovale wallikeri infection in Chongqing in 2015. J Trop Dis Parasitol. 2016;14(3):141-4. (in Chinese)

27. Tang HW. Epidemiological survey on the first imported falciparum malaria case in Bozhou City. Anhui Province J Trop Dis Parasitol. 2012;10(2):95-6. (in (hinese)

28. Ren HB, Zhang YS, Zhou JS, Wu B, Xia LS. A case report: imported Plasmodium vivax from Pakistan. Chin J Parasitol Parasit Dis. 2005;23(4):239. (in Chinese)

29. Lu XY, Deng JG, Yu SL, Huang XL, Huang YM. Investigation of a case of foreign imported falciparum malaria in Xilin County. Baise City Chin J Schisto Control. 2017:1-3. (in Chinese)

30. Huang YT, Yang YJ, Zhang JJ, He ZY, Wang XM. A case report of one letha case of imported Plasmodium falciparum in Beijing. Chin J Parasitol Parasit Dis. 2012;30(4):324. (in Chinese)

31. Luo YN. Case report: first case of Plasmodium falciparum in Cixi City. Chin J Parasitol Parasit Dis. 2009;27(3):194. (in Chinese)

32. Zhao JY. A case investigation: four case of imported Plasmodium falciparum in Ezhou City. J of Pub Health and Prev Med. 2011;22(6):85. (in Chinese)
33. Wang WS, Chen GY, Zhang HP, Guo EC, LI XQ, LI DM, et al. Case investigation of first imported Plasmodium falciparum in Fangcheng County. Chin J Parasit Dis Con. 2002;15(6):345. (in Chinese)

34. Zhang ZP, Wei HZ, Lin YY, Zuo MY, Zhang HC, Zhu HM. Diagnosis of an imported case of Plasmodium ovale infection in Nanping City. Fujian Chin J Parasitol Parasit Dis. 2015;33(1):72-3. (in Chinese)

35. Li LS, Xie HG, Ouyang R, Wu JJ. A case report: imported Plasmodium malariae in Fujian Province. Chin J Zoonoses. 2005;21(5):442. (in Chinese)

36. Shi YX, Huang JC, Su JK, Li XB, Zheng K, Ding GY. Diagnosis of the first imported case of malaria ovale at Guangdong port. Chin J Parasitol Parasit Dis. 2014;32(2):156-7. (in Chinese)

37. Yu YJ, Cao H, Chen SR, LI MY, Yang X, Zhan XM. An imported Plasmodium falciparum case in Guangdong. Chin J Parasitol Parasit Dis. 2012;30(2):94-5. (in Chinese)

38. Liu Y, Zhang Y, IU FR. A case report: one imported Plasmodium falciparum in Harbin City. Chin J Parasitol Parasit Dis. 2011;29(3):81. (in Chinese)

39. Lin YY, Zhang SY, Xie HG, Ouyang R, Yang FZ, Chen ZY. Rare imported Plasmodium ovale wallikeri subspecies PCR identification and sequencing analysis. J Pathogen Bio. 2014;9(10):905-7. (in Chinese)

40. Wu ZR, Yan JH, Fu XJ, Zhang M, Shen J. A foreigner imported case report: mixed infection of dengue fever and Plasmodium falciparum. Chinese Frontier Health Quarantine. 2014;37(3):215-6. (in Chinese)

41. Deng Y, Zhou RM, Zhang HW, Qain D, Liu Y, Chen WQ, et al. Diagnosis and treatment for imported Plasmodium malariae malaria case in Henan Province. Chin J Parasitol Parasit Dis. 2014;32(1):61-3. (in Chinese)

42. Shun LC, Zhang HX, Pei SJ, Xia J, Wu DN, Lin W. Analysis on etiological diagnosis of first case of imported Plasmodium ovale wallikeri subspecies in Hubei Province. Int J Lab Med. 2016:2016(14):1956-7. (in Chinese)

43. Fan JB, Li BA, Liu HJ. An imported malaria case report: Plasmodium ovale in Xiangyang City in Hubei Province. Chin J Parasitol Parasit Dis. 2017;35(4):1. (in Chinese)

44. Li SH, Cai YF, Yuan FY, Pei SJ, Hu YQ, Shi BF, et al. A case report of imported Plasmodium falciparum in Zhongxiang City in Hubei Province. Chin J Parasitol Parasit Dis. 2010;28(6):478. (in Chinese)

45. Jiang CG, Chen SJ, Li YM. A case report of imported Plasmodium falciparum in Jurong City in Jiangsu. Chin J Parasitol Parasit Dis. 2012;30(6) (in Chinese)

46. Hu ZH, Fu RL, Peng GH, Cai DT, Guo J. An imported case of Plasmodium ovale infection in Nanchang City of Jiangxi Province. Chin Trop Med. 2016; 16(6):623-5. (in Chinese)

47. Shui MM, Zhao S, Li J, Xu Y. One case of overseas imported quartan malaria. Chin J Schisto Control. 2015;27(3):332-4. (in Chinese)

48. Wang HM. Two imported case of Plasmodium falciparum in Panjing in Liaoning. Chin J Parasitol Parasit Dis. 2013;31(5):345. (in Chinese)

49. Huang JX, Yang JQ, Peng ZX. Epidemiological investigation and measures of the first imported falciparum malaria at Luohu port. In: 2012 academic symposium of Shenzhen municipal preventive medicine association; 2012. p. 681-3.

50. Li QR. An imported falciparum malaria case in Puyang City. Med Res Henan. 2000;10:254. (in Chinese)

51. Tan JP, Wang Y, Wang HY. An imported falciparum malaria case in Qiannan. Journal of Qiannan Medical College for Nationalities. 2016;29(4):270. (in Chinese)

52. Miao $P, X i a ~ J H, C h e n ~ H X$. The first imported case of falciparum malaria in Rudong County. Shanghai J Prev Med. 2010;22(3):163. (in Chinese)

53. Miao P, Chen HX. Investigation of an imported vivax malaria case in Rudong County. Jiangsu J Prev Med. 2011;22(4):53. (in Chinese)

54. Tian B, Duan JH, Xu MZ, Zhang B, Liao Y, Shen XJ, et al. Laboratory diagnosis on three imported cases of ovale malaria. Lab Med 2014; 29(8): 851-854. (in Chinese)

55. Wang YB, Li J, Kong XL, Xiao T, Zhang BG, Zhao S, et al. The first report of a case of imported quartan malaria in Shandong Province. J Pathogen Bio. 2013;8(12) (in Chinese)

56. Li Y, Zou PP, Lu L, Jin LF. A lethal case report of imported falciparum malaria in Fenxian District in Shanghai City. Chin J Parasitol Parasit Dis. 2010; 28(2):88. (in Chinese)

57. Xiao T, Li JM, Liu F, Li J, Huang BC, Wang YB, et al. Two case report of the imported ovale malaria in Shandong Province. J Pathogen Bio. 2012;7(6) (in Chinese)

58. Wang XH. A case report of imported falciparum malaria. J Navy Med. 2004; 25(2):185-6. (in Chinese)

59. Feng Q. A case report of imported falciparum malaria. Guangdong J Health Epidemic Prev. 1999;25(2):95-6. (in Chinese) 
60. Wang B, Hu DY. A case report of imported falciparum malaria. J Prev Med Inf. 2009;25(11):974. (in Chinese)

61. Yang GS, Zhu FB, Zhang Y. A case report of imported falciparum malaria. Chin J Parasitol Parasit Dis. 2012;30(3):1. (in Chinese)

62. Zheng HS. A case report of imported falciparum malaria. Chin J Parasit Dis Con. 2004:17(4):202. (in Chinese)

63. Zheng XM, Lv J, He HG, Huang JQ, Hu LQ. A first lethal case report of imported falciparum malaria in Shiyan City. Chin J Parasitol Parasit Dis. 2011; 29(1):76-7. (in Chinese)

64. Zhou ZH, Wu MS, Wang QJ. A case report of imported falciparum malaria. Chin J Clin Lab Sci. 2011;29(3):204. (in Chinese)

65. Wang ZM. A case report of imported falciparum malaria. Journal of Anhui Health Vocational \& Technical College. 2015;14(6):97-8. (in Chinese)

66. Xu YC, Wei SL, You TT, Su Q, Feng J, Yin Q. Imported falciparum malaria: one case report and literature review. Chin J Schisto Control. 2015;27(1): 108-9. (in Chinese)

67. Li YX. Survey on two lethal imported falciparum malaria cases due to misdiagnosis. Chin Trop Med. 2013;13(8):1043-4. (in Chinese)

68. Dai YR, Zhou XH, Zhuang JQ, Lin XH, Li T, Hou YS, et al. An important falciparum malaria cases died of multiple organ failure. Chin Trop Med. 2010;10(12):1528. (in Chinese)

69. Chen YF, Xu FL, Zhou LX. A cases report of imported falciparum malaria complicated with Blackwater fever. Chin J Parasit Dis Con. 1991;4(2):153. (in Chinese)

70. Cui XB, Fang ZB. One death case of imported falciparum malaria. Prev Med Trib. 2011;17(3):245-6. (in Chinese)

71. Xu GJ, Yang K, Lai Q, Lei Y. Four death cases of imported falciparum malaria. Chin J Parasitol Parasit Dis. 2006;24(3):165. (in Chinese)

72. Chen YM, Qian L. A misdiagnosis case of imported falciparum malaria. Chin J Parasitol Parasit Dis. 2002;20(1):48. (in Chinese)

73. Wu K, Yang Y, Zhou SM, Xu MX. A case report: mixed infection of Toxoplasma and Plasmodium falciparum. Chin J Parasitol Parasit Dis. 2015; 33(3) (in Chinese)

74. Guo CK, Lin Z, Qin YX. A case report of imported recurrent vivax malaria. Guangxi Prev Med. 2003;9(5):276. (in Chinese)

75. Li LM, Fu ZM, Fan LH. A case of imported vivax malaria. Lab Med Clin. 2014; 11(1):138-9. (in Chinese)

76. Zhao ZH, Meng QW. Two cases report of imported cerebral malaria. J Pathogen Bio. 2009;4(7) (in Chinese)

77. Zheng SN, Chen YF, Zhou LX, Ma QQ, Zhou ZQ. A case report of imported malariae malaria. Chin J Parasitol Parasit Dis. 1988;6(3):185. (in Chinese)

78. Wang PP, Hu GZ, Zhou HZ, Wu ZY. Laboratory test of a case of imported malariae malaria. Modern Practical Medicine. 2016;28(4):559-60. (in Chinese)

79. Leng XJ, Yang YX. Medical care of a pediatric case of imported cerebral falciparum malaria. J Trop Dis Parasitol. 2012;10(4):245. (in Chinese)

80. Li AM, You XC, Lu DL. A case report of imported falciparum malaria. Chin Parasit Dis Con. 1995;8(1):60. (in Chinese)

81. Chen B, Shen D, Xu ZM, Fan JB. Two severe cases of imported falciparum malaria. Chin J Parasitol Parasit Dis. 2014;32(4) (in Chinese)

82. LI M, Zhong L, Qiu JL. A severe case report of cerebral falciparum malaria. Chin J Parasito Parasit Disl. 2006;24(6) (in Chinese)

83. Wu TH, Ge HM, Ding JM, Chen X, Ma J, Zang L. Investigation and disposal of an imported vivax malaria. Chin J School Doctor. 2010;24(3):173. (in Chinese)

84. Yao LN, Zhu TP, Jin XY, Xia SY, Xu WM. A death case report of imported falciparum malaria due to misdiagnosis. Chin Trop Med. 2003;3(6):777. (in Chinese)

85. Chen K. Survey on two cases of imported falciparum malaria. China J of Pharm Econ. 2014;5 (in Chinese)

86. Zhou RM, Zhang HW, Deng Y, Qian D, Liu Y, Chen WQ, et al. Laboratory detection on two cases with imported Plasmodium ovale infection. Chin J Parasitol Parasit Dis. 2013;31(2) (in Chinese)

87. Wang H, Xie N, Di W, Li Y, Yang N, Li PR, et al. Rapid detection of three cases of imported Plasmodium falciparum. Labeled Immunoassays \& Clin Med. 2015;22(8):718-9. (in Chinese)

88. Zhou DC, Li WG, Ma YC, Diao ZT, Wei DC. Investigation on imported malaria and local outbreak in Pu Yi town, Pu'er county, Yunnan. J Pract Parasitic Dis. 1999;7(32) (in Chinese)

89. Wu XZ, Hu YH. Report of one case of severe falciparum malaria in Suzhou. J Trop Dis Parasitol. 2012;10(4):244. (in Chinese)

90. Wang WM. Analysis of imported Plasmodium falciparum malaria cases in Taizhou Province in 2011. Mod Prev Med. 2014;41(15):2858-9. (in Chinese)
91. Ni QX, Zhang XH, Chen Y, Yu XH, Wei JJ, Pan QJ. Report of 2 cases of imported ovale malaria in Wenzhou City. Zhejiang Prev Med. 2015;27(2):178. (in Chinese)

92. Pei SJ, Gui AF, Huang GQ, Xu MX, Wang CX, Mao CX. Investigation and disposal of two cases of imported falciparum malaria in Wuhan. J Public Health Prev Med. 2006;17(6):52. (in Chinese)

93. Wang ZT, Li JL. Investigation, treatment and follow up of an imported falciparum malaria in Wuxue City. Hubei J Prevent Med. 2004;15(2):23. (in Chinese)

94. Zhang HM, Chen HL, Zhang LL, Jin HY, Lu QY, Jin GN, et al. Diagnosis and treatment of the first imported ovale malaria case in Xihu District. Zhejiang Prev Med. 2015;27(10):1043. (in Chinese)

95. Zhang $\mathrm{JH}$. Investigation and disposal of the first imported falciparum malaria in Xiaochang County. J Community Med. 2014;12(4):70-1. (in Chinese)

96. Chen XJ, Dong WB, Hu CY, Wang LX. Investigation and disposal of a family outbreak of imported falciparum malaria in Xiaonan District, Xiaogan City. J of Pub Health and Prev Med. 2012;23(4):64. (in Chinese)

97. Wang LB, He B, Chen FX, Li YG. Survey on two imported falciparum malaria case in Xinjiang. Chin Trop Med. 2013;13(12) (in Chinese)

98. Jiang $L$, Wang XD. A case report of an imported ovale malaria from Gabon. Chin Trop Med. 2013;13(9):1169. (in Chinese)

99. Li XH, Gao ST, Pei FQ, Ruan CW, Pan B, Wang DN, et al. Epidemiological investigation of a case of imported Plasmodium malariae infection of a 2 years old boy. J Trop Med 2016; 6(8):1008. (in Chinese).

100. Cui XB, Ke H, Kong QP, Hu QL. A case report of imported dengue fever combined with falciparum malaria. J of Pub Health and Prev Med. 2011; 22(4):78. (in Chinese)

101. He HG, Tang GZ. Experience in treatment of an imported falcipaum malaria case. Chin Trop Med. 2014;14(4):510. (in Chinese)

102. Xiong Y, Zhang ZB, Shen H. A rescue report of a severe malaria case coinfected with Plasmodium falciparum and Plasmodium vivax. Chin Trop Med. 2014;14(7) (in Chinese)

103. Xie XG. A death case report of imported falciparum malaria. J Pract Parasitic Dis. 1996:4(2):92. (in Chinese)

104. Fan $K$, zhang $X Y$, Mo $X Y$, Song $Y$. Investigation on a case of recurrent vivax malaria. Chin J of PHM 2012; 28(1):69. (in Chinese).

105. Su LJ, He LJ, Liang MQ, Lu ZB. An imported case of mixed infection with Plasmodium vivax and Plasmodium falciparum. Applied Prev Med. 2010;16: 92. (in Chinese)

106. Shang LY, Yan QY, Li AM. Misdiagnosis of three cases of malaria infected by blood transfusion. Henan J Prev Med. 1994;5(6):364. (in Chinese)

107. Jiang J, Liu JH, Li QY. Control and management of an imported falciparum malaria case in Yichang city. Chin Trop Med. 2013;13(3):348. (in Chinese)

108. Zeng Y, Cai AH, Zhu HB, Ni XM, Ke Z. Diagnosis of an imported falciparum malaria case by fluorescence quantitative PCR. Chin J Parasitol Parasit Dis. 2014;32(4):316-7. (in Chinese)

109. Deng SM, Fang YM, Li GS, Huang QG, Mou HJ. First case of imported falciparum malaria in Yunmeng County. J of Pub Health and Prev Med. 2012;23(1):88. (in Chinese)

110. Yang JH, Li JQ, Sun XD. Diagnosis and treatment of an imported severe falciparum malaria patient in Baoshan City. Yunnan Province Chin Trop Med. 2016;16(06):626-7. (in Chinese)

111. Jiang ZH. Imported Plasmodium falciparum infection from Laos: a case report. Chin J Parasitol Parasit Dis. 2003;21(1):8. (in Chinese)

112. Huang JR, Liu SF, Ye AQ, Wu GL, Liu FM, Yang L. Two case observation: treatment of imported chloroquine-resistant falciparum malaria. Chin J Parasitol Parasit Dis. 1991;9(1):27. (in Chinese)

113. Cui J, Wang ZQ, Wu F, Jin XX, Mao FR. A case report of imported vivax malaria in a Zhengzhou college student. Henan J Prev Med. 1995;6(3):139. (in Chinese)

114. Wang ZT, Li QS, Cai GB. Investigation on a local outbreak of imported vivax malaria in Anxi County, Fujian Province. Chin J Parasitol Parasit Dis. 1998; 16(2):156. (in Chinese)

115. Li L, Xu ZL, Xu RS, Shi CY. A case report of imported falciparum malaria. Shanghai J Prev Med. 1994;6(10):47. (in Chinese)

116. Zhou WX, Mo ZJ, Pan GX. A misdiagnosis case of falciparum malaria. Chin J Parasitol Parasit Dis. 1997;15(2):118. (in Chinese)

117. Xiong B, Wang F. Two cases of imported vivax malaria. Chin J Parasitol Parasitic Dis. 2008;26(5):373. (in Chinese)

118. Xiao BZ. A death case report of imported chloroquine-resistant falciparum malaria. J Pract Parasitic Dis. 1993;1(4):26. (in Chinese) 
119. Liu GC, Peng RC. A case report of imported cerebral falciparum malaria. Chin J Parasit Dis Con. 1996:9(3):227. (in Chinese)

120. Liu TL. Li SF. A report of three imported long-latency vivax malaria cases. Guangdong Med J. 1987;4(30) (in Chinese)

121. Tang RS. An outbreak of imported vivax malaria in Lu County in Sichuan Province. Chin J Parasitol Parasit Dis. 1994;20 (in Chinese)

122. Wang CZ, Yang JY, Chen Y, Yan JC. Investigation and disposal of two cases of Plasmodium falciparum malaria in Changnin in Sichuan. J of Pract Parasitic Di. 1999;7:32-3. (in Chinese)

123. Zou J, Xuan SZ, Wang J. A case of imported falciparum malaria. Anhui J Prev Med. 1997;3(2):49. (in Chinese)

124. Lei CF. A case of imported chloroquine-resistant falciparum malaria. J Pract Parasitic Dis. 1995;3(3):144. (in Chinese)

125. Wan JJ, Xu L, Wu ZS, Xu J, Chen L, Liu Y, et al. Schistosomiasis control progress and endemic situation in Sichuan Province. Chin J Schisto Control 2016; 6(28):713-716. (in Chinese).

126. Chen XY, Jiang QW, Wang LY, Zhao GM, Zhao Q, Wei JG, et al. Schistosomiasis situation in people 's republic of China in 2001. Chin J Schisto Control. 2002; 14(4):241-243. (in Chinese).

127. Chen XY, Wu XH, Wang LY, Dang H, Wang Q, Zheng J, et al. Schistosomiasis situation in People's Republic of China in 2002. Chin J Schisto Control. 2003; 15(4):241-4. (in Chinese)

128. Xiao DL, Yu Q, Dang H, Guo JG, Zhou XN, Wang LY. Schistosomiasis situation in People's Republic of China in 2003. Chin J Schisto Control. 2004; 16(6):401-4. (in Chinese)

129. Hao Y, Wu XH, Xia G, Zheng H, Guo JG, Wang LY, et al. Schistosomiasis situation in People's Republic of China in 2004. Chin J Schisto Control. 2005; 17(6):401-4. (in Chinese)

130. Hao Y, Wu XH, Xia G, Zheng H, Guo JG, Wang LY, et al. Schistosomiasis situation in People's Republic of China in 2005. Chin J Schisto Control 2006; 18(5):321-324. (in Chinese).

131. Hao Y, Wu XH, Zheng H, Wang LY, Guo JG, Xia G, et al. Schistosomiasis situation in People's Republic of China in 2006. Chin J Schisto Control 2007; 19(6):401-404. (in Chinese).

132. Hao Y, Wu XH, Zheng H, Wang LY, Guo JG, Xia G, et al. Schistosomiasis situation in People's Republic of China in 2007. Chin J Schisto Control 2008; 20(6):401-404. (in Chinese).

133. Hao $Y$, Zheng H, Zhu R, Guo JG, Wu XH, Wang LY, et al. Schistosomiasis situation in People's Republic of China in 2008. Chin J Schisto Control 2009; 21(6):451-456. (in Chinese).

134. Hao Y, Zheng H, Zhu R, Guo JG, Wang LY, Chen C, et al. Schistosomiasis situation in People's Republic of China in 2009. Chin J Schisto Control. 2010; 22(6):521-526. (in Chinese).

135. Lei ZL, Zheng H, Zhang LJ, Zhu R, Guo JG, Li SZ, et al. Schistosomiasis situation in People's Republic of China in 2010. Chin J Schisto Control. 2011; 23(6):599-604. (in Chinese)

136. Zheng H, Zhang LJ, Zhu R, Xu J, Li SZ, Guo JG, et al. Schistosomiasis situation in People's Republic of China in 2011. Chin J Schisto Control 2012; 24(6):621-626. (in Chinese).

137. Li SZ, Zheng H, Gao Q, Zhang $\sqcup$, Zhu R, Xu J, et al. Endemic status of schistosomiasis in People's republic of China in 2012. Chin J Schisto Control 2013; 25(6):557-563. (in Chinese).

138. Lei ZL, Zheng $H$, Zhang LJ, Zhu R, Xu ZM, Xu J, et al. Endemic status of schistosomiasis in People's republic of China in 2013. Chin J Schisto Control 2014: 26(6):591-596. (in Chinese).

139. Lei ZL, Zhang LJ, Xu ZM, Dang H, Xu J, Lv S, et al. Endemic status of schistosomiasis in People's republic of China in 2014. Chin J Schisto Control. 2015;27(6):563-9. (in Chinese)

140. Zhang LJ, Xu HM, Qian YJ, Dang H, Lv S, Xu J, et al. Endemic status of schistosomiasis in People's Republic of China in 2015. Chin J Schisto Control 2016; 28(6):611-617. (in Chinese).

141. Li YR, Xie GH, Chen ZY, Xiao LZ, Zhang RY. Diagnosis and treatment of an imported case of schistosomiasis haematobium. Chin J Schisto Control. 2017:29(1):108-10. (in Chinese)

142. Gao JX, Yao Y, Zhao YY, Zhang JY. Case report of one imported schistosomiasis cases in Linyi. Shandong Int J Med Parasit Dis. 2015;42(5):294-5. (in Chinese)

143. Zhu SJ, Wang H, Xu WM, Yang Y, Tang Y, Wang J. First case report of imported schistosomiasis in Zhejiang Province. Prev Med. 2016:28(10):1021-2. (in Chinese)

144. Zheng QF, Chu BY, Chen YY, Yang P, Yang P, Jin GB, et al. First case report of imported schistosomiasis in Taizhou, Zhejiang. Chin J Parasitol Parasit Dis 2017; 35(1):17-18. (in Chinese).
145. Zhang JF, Wen LY, Zhu R, Yan XL, Guo JG, Qian K, et al. First case of imported schistosomiasis mansoni in Zhejiang. Chin J Parasitol Parasit Dis. 2014;32(3) (in Chinese)

146. Hua HY, Wang W, Cao GQ, Tang F, Liang YS. Improving the management of imported schistosomiasis haematobia in China: lessons from a case with multiple misdiagnoses. Parasit Vectors. 2013;6:260.

147. Xie HG, Lin CX, Jiang DW, Xie XL, Li LS, Yang FZ, et al. A case of imported schistosomiasis haematobia first reported in Fujian Province. Chin J Schisto Control. 2013;25(3) (in Chinese)

148. Wang YL, Wang J, Zhang J, Zhang Q, Qian C. Retrospective analysis of two cases of imported schistosomiasis haematobia in Henan province. Chin Front Health Quarantine. 2017;40(3):188-9. (in Chinese)

149. Jiang L, Wang XD, Huang F. Report of two cases of imported schistosomiasis in Zhangjiagang. China Med Pharm. 2011;1(15):181. (in Chinese)

150. Li M, Wang SH, Chen ZY, Ye HB. A case report of imported schistosomiasis in Guizhou. Chin J Zoonoses. 2007;23(1):100. (in Chinese)

151. Chen PF. Imported schistosomiasis in Jinhua City: two case report. Chin J Schisto Control. 2006;18(1):14. (in Chinese)

152. Wu MJ. Investigation of an imported schistosomiasis. In: The 12th academic conference of rural medicine and the management of township health centers in Zhejiang.78.

153. Zhang JN. Two imported cases of schistosomiasis in Ningbo. Zhejiang Prev Med. 2004;16(12):28-9. (in Chinese)

154. Huang SY, Chen ZC, Pan B, Huang HY, Lv YF, Lin RX, et al. Epidemiological investigation of imported human schistosomiasis in Doumen County. South China J Prev Med. 2002;28(5):34-5. (in Chinese)

155. Shi BN, Yu J. An imported case of schistosomiasis. Chin J Zoonoses. 2000; 16(3):37. (in Chinese)

156. Chen ZY, Xie HG, Lin RY, Zhang SY. First imported Rhodesian human African trypanosomiasis in China. Chin J Zoonoses. 2018; https://doi.org/10.3969/j. issn.1002-2694.2018.00.052. (in Chinese)

157. Zhou TC, Shun JL, Wu WP, Shi GQ, Li ZJ. Investigation on an imported case of Loaiasis. Dis Surveill. 2016;31(9):796. (in Chinese)

158. He ZY, Wang XM, Li XT, Li X. Imported loaiasis in Beijing: epidemiological characteristics in 5 patients. J Trop Dis Parasitol. 2016:14(2):74. (in Chinese)

159. Sun Yi, Huang WH, Niu ZG, Wang H, Guo J, Hu XX, et al. Pathogen identification for an imported case with African trypanosomiasis. Chin J Parasitol Parasit Dis. 2016; 34(4):350-352. (in Chinese).

160. Xu X, Yao LN, Zhang JY, Xia SR, Chen HL, Ruan W. One imported case of loiasis. J Pathogen Bio. 2008;3(12):926. (in Chinese)

161. Weng YF, Zhang XQ. Investigation and analysis of the first imported loaiasis in Dinghai District in Zhoushan City. Chin Prev Med. 2010;11(2):205. (in (hinese)

162. Song LG, Zheng XY, Lin DT, Wang GX. Wu ZD. Parasitology should not be abandoned: data from outpatient parasitological testing in Guangdong, China. Infect Dis Poverty. 2017:6(1):119.

163. Huaxia. China builds more amicable, Vibrant neighborhood with belt and road initiative. 2015. http://www.xinhuanet.com/english/2015-12/28/c 134958396.htm. Accessed 28 Dec 2015

164. Administration CNT. China Tourism: 2016 Statistics and 2017 Economic Predictions 2016. 2017. http://bjsq.cnta.gov.cn/eng/sjzx_4026/lytjgb_4027/ 201710/t20171013_842558.shtml. Accessed 19 Oct 2017.

165. Administration CNT. China Tourism Statistical Bulletin 2014. 2017. http://bjsq cnta.gov.cn/eng/sjzx_4026/lytjgb_4027/201710/t20171013_842560.shtml. Accessed 19 Oct 2017

166. Administration hNT. China Tourism Statistical Bulletin 2015. 2017. http:// encntagovcn/Statistics/TourismStatistics/201710/t20171013_842559s.html. Accessed 19 Oct 2017

167. Wang W, Liang YS, Hong QB, Dai JR. African schistosomiasis in mainland China: risk of transmission and countermeasures to tackle the risk. Parasit Vectors Parasit Vectors. 6(1):249.

168. Liang YS, Wang W, Hong QB, Dai JR. Risk assessment and control measures for import of African schistosomiasis into China. Chin J Schisto Control. 2013:25(3):221-5. (in Chinese)

169. Editor. Introduction of American trypanosomiasis. Dis Surveill. 2012;27(5):488 